\title{
A Mística no contexto do movimento da Educação do Campo
}

The Mystic phenomenon in the context of the countryside education movement Ozana Luzia Galvão Baldotto Ailton Pereira Morila

Resumo: Esse artigo é parte de uma pesquisa realizada no mestrado em Ensino na Educação Básica da Universidade Federal do Espírito Santo (UFES), financiada pela bolsa de estudos da Coordenação de Aperfeiçoamento de Pessoal de Nível Superior (CAPES). A pesquisa contextualizou os elementos pedagógicos das propostas pedagógicas das Escolas do Campo nos Municípios de Jaguaré e São Mateus, localizados no Estado do Espírito Santo. Os elementos pedagógicos pesquisados foram: o Plano de Estudo/Ficha de Pesquisa; a Auto-organização; a Mística; a Pasta da Realidade/Caderno da Realidade/Portfólio; o Caderno de Planejamento e Reflexão/Caderno de Acompanhamento; as Atividades/Conteúdos Vivenciais (visita/viagem de estudo, oficina/experiências, intervenções/palestras); a Visita às Famílias. A pesquisa envolveu 6 (seis) escolas, com foco nos anos iniciais do Ensino Fundamental, com abrangência em 3 (três) unidades escolares no Município de Jaguaré e 3 (três) no Município de São Mateus. Neste artigo trataremos sobre a Mística, considerando os apontamentos da pesquisa nas unidades escolares. A Mística é considerada um elemento essencial no projeto pedagógico das escolas do campo por possibilitar o envolvimento dos diversos povos do campo na construção e fortalecimento desse projeto. A metodologia utilizada foi a História Oral Temática, com entrevistas gravadas, deixando o entrevistado à vontade para dialogar sobre o tema pesquisado. As entrevistas envolveram educadores, estudantes, representantes de pais e lideranças comunitárias das escolas pesquisadas.

Palavras-chave: Mística. Elemento Pedagógico. Educação do Campo. Proposta Pedagógica.

Abstract: The current article is a part of a research conducted in the Masters' degree on
Federal University of Espírito Santo (UFES) sponsored by CAPES (Coordination for the
Improvement of Higher Education Personnel). This research contextualizes pedagogical
elements from the proposals of the Countryside School's proposals in São Mateus and
Jaguaré, cities in the north of Espírito Santo state. The researched pedagogical elements
were the following: The study plan/ research form, the self-organization, the mystical, the
reality copybooks, the planning and reflections copybooks/ follow up copybooks; the
activities/ living contents (visits/study trips, workshops/experiences,
lectures/interventions), family visits. This research has engaged 6 schools focusing on
the elementary school. 3 schools in Jaguaré city and 3 schools situated in São Mateus
city. This article article discusses the mystical taking account the schools research notes.
The mystical is considered an essential element of the countryside schools' pedagogical
projects due to its possibility of involving different folks from the countryside in the
construction and fortification of such project. The methodology used was Oral Thematic
History, with recorded interviews, leaving the interviewee free to discuss the researched
topic. The interviews involved educators, students, parents, representants and
community leaders from the schools surveyed. Key-words: mystical. Pedagogical element. Countryside school. School Pedagogical Proposal. 


\section{Introdução}

"A Mística tem um valor significativo, não é só uma apresentação.

Ela tem o seu sentido, é pura reflexão.

Me alerta, chama-me a atenção, mexe com minha consciência e com todo meu coração. [...]

Mostra de forma rápida e decidida, uma coisa que já foi vivida, como forma de relembrar e reviver para nunca esquecer.

Sempre me ensina uma coisa legal, a lidar com coisas do bem e do mal.

Ensina-me não só a preservar o meio ambiente, mas a próxima geração, dos meus filhos e netos que virão.

Por fim, dá-me uma lição, de que a Mística ajuda na minha formação." Wesley Pereira

O termo Educação do Campo foi gestado a partir do primeiro Encontro Nacional de Educadores(as) da Reforma Agrária (ENERA), realizado em 1997, promovido pelo Movimento dos Trabalhadores Rurais Sem Terra - MST, Universidade de Brasília - UNB, Organização das Nações Unidas para a Educação, Ciência e Cultura - UNESCO, Fundo das Nações Unidas para a Infância - UNICEF e Conferência Nacional dos Bispos do Brasil - CNBB.

A I Conferência Por Uma Educação Básica do Campo, realizada em Luziânia-GO, em 1998, representou o alinhamento e fortalecimento das discussões iniciadas no I ENERA. Efetivamente, representou a ratificação do movimento pela Educação do Campo no Brasil.

Em 2004, com a Il Conferência Nacional de Educação do Campo, definiuse a ampliação de novos caminhos de luta, sinalizando a construção de um processo histórico da educação, conduzido e organizado pelos sujeitos sociais do território campesino.

Esse movimento realizou estudos e debates sobre a construção do projeto de educação nas escolas do campo, mas não qualquer escola: buscava-se uma escola voltada para as lutas e as necessidades dessa população. Já existiam, 
entretanto, as Escolas Famílias Agrícolas - EFA's ${ }^{1}$, que utilizavam a Pedagogia da Alternância, metodologia criada na França para o ambiente rural.

De acordo com Zamberlan (1995, p.3) a história das EFA's teve início no Espírito Santo, por meio de uma ação pastoral envolvendo várias lideranças comunitárias e diversas forças sociais. Esse trabalho de base iniciou-se por volta dos anos 65/66, pela ação do Pe. Jesuíta Humberto Pietrogrande. As primeiras Escolas foram inauguradas no norte do Estado do Espírito Santo a partir de 1972.

Essa experiência influenciou, posteriormente, as escolas de Assentamentos mantidas pelo Estado e, em alguns casos, por Municípios. Surgem também, as Escolas Comunitárias Rurais ligadas à rede municipal de ensino em vários Municípios do Estado do Espírito Santo, como: Jaguaré, Barra de São Francisco, Mantenópolis, Ecoporanga, Nova Venécia, Rio Bananal, Colatina e São Mateus.

O trabalho com elementos da Pedagogia da Alternância, gradativamente, foi inserido na prática pedagógica dos anos iniciais do Ensino Fundamental a partir da década de 80 , pelas escolas de assentamentos e pelas escolas do Município de Jaguaré a partir de 2000, e, posteriormente em 2008, nas escolas municipais de Colatina e nas escolas municipais de São Mateus, a partir de 2012.

A pesquisa realizada teve como objetivos contextualizar as propostas pedagógicas $^{2}$ dos anos iniciais do Ensino Fundamental das escolas do campo e analisar o processo ensino e aprendizagem a partir da utilização dos elementos contidos nessas propostas em escolas dos Municípios de Jaguaré e São Mateus.

\footnotetext{
${ }^{1}$ As Escolas famílias Agrícolas ligadas ao Movimento de Educação Promocional do Espírito Santo - MEPES, são instituições filantrópicas que oferecem as séries finais do Ensino Fundamental e em algumas localidades, até o Ensino Médio. O trabalho realizado pelas Escolas Famílias Agrícolas - EFA's, Casas Familiares Rurais, Escolas Comunitárias Rurais, utilizam os princípios educativos com a formação baseada em distintos tempo caracterizados como: período escolar (tempo) que se alterna com períodos no meio familiar (tempo).

${ }^{2}$ Foram analisados documentos específicos que direcionam o trabalho pedagógico nas escolas do campo como o PROVER (Programa de Valorização da Educação Rural do Município de Jaguaré), o PLAFEC (Plano de Fortalecimento da Educação do Campo do Município de São Mateus) e as Diretrizes das Escolas de Assentamentos e Acampamentos da Rede Estadual de Ensino do Estado do Espírito Santo.
} 
A pesquisa foi realizada em 6 (seis) escolas, com foco nos anos iniciais do Ensino Fundamental, incluindo 3 (três) unidades no Município de Jaguaré e 3 (três) no Município de São Mateus. Em Jaguaré, duas escolas estão em território de agricultura familiar e uma em território de assentamento. Em São Mateus, uma unidade localizada em território de assentamento, uma em território quilombola e outra em região de pesca.

A metodologia utilizada foi a História Oral Temática, que consiste em realizar entrevistas abertas e gravadas com pessoas que podem testemunhar sobre acontecimentos, conjunturas, instituições, modos de vida ou outros aspectos da história contemporânea (MEIHY; HOLANDA, 2010). A presença do pesquisador é fundamental por incentivar o narrador durante a o diálogo, perguntando à medida que o assunto é explanado. Essa metodologia possibilita um diálogo aberto sobre o tema pesquisado, por deixar o colaborador livre para falar sobre $o$ assunto.

Nesse contexto, a pesquisa nas escolas aconteceu por meio de diálogos envolvendo educadores de escolas do campo, representantes de pais, lideranças das comunidades e estudantes.

Além das histórias orais gravadas e transcritas, foram pesquisados documentos referentes à Educação do Campo nos Municípios de Jaguaré e São Mateus, documentos do Movimento dos Trabalhadores Rurais Sem Terra - MST, bem como uma bibliografia específica.

A pesquisa teve como foco inicial o "fazer pedagógico" com utilização do Plano de Estudo, no entanto os entrevistados trouxeram os diversos elementos pedagógicos que interagem juntamente com o Plano de Estudo: a Mística, a Auto-organização, o Caderno da Realidade e o Caderno de Acompanhamento.

Esse artigo abordará uma parte da pesquisa realizada, onde será evidenciada a Mística como elemento pedagógico no contexto das escolas pesquisadas. 


\section{A Mística na Educação do Campo}

A Mística é um fenômeno que se expressa numa liturgia, ou seja, numa linguagem de símbolos que une a palavra ao gesto, revigora a memória e fortalece a luta, uma causa, um projeto (SAMPAIO, 2002).

A Mística ultrapassa a liturgia religiosa e contempla outras formas a partir do momento que a sociedade passa a utilizá-la no cotidiano. O MST a utiliza como instrumento que "alimenta o sonho" e representa a mola propulsora da luta social, considerada como "algo que move" a caminhada (BOGO, 2002).

Nesse contexto, a Mística expressa-se através da poesia, do teatro, da expressão corporal, de palavras de ordem, da música, do canto, dos símbolos, das ferramentas de trabalho, do resgate da memória e se torna um momento de celebração que envolve os diversos sujeitos em um mesmo objetivo do coletivo (MOVIMENTO DOS TRABALHADORES RURAIS SEM TERRA, 1999).

Nessa perspectiva, Frei Betto (2010, p. 106) destaca a importância da Mística:

Será que é possível construir homens e mulheres novos sem falar de Mística? A Mística está para esta questão como a química do solo para produzir os bons frutos. Temos de quebrar o tabu e o preconceito de falar sobre esse tema, que precisa ser discutido até numa mesa de bar, porque senão repetiremos o erro de nossos companheiros do socialismo, com toda uma ideologia objetivista das coisas, sem considerar a questão da subjetividade.

A Mística faz parte da sociedade - embora com significados diferenciados - como a Mística do futebol, a Mística do carnaval. Está presente como um elemento da sociedade que passa por transformações considerando o momento cultural, social e econômico de cada sujeito social e de cada localidade.

O termo "Mística" possui diversos significados e para o Dicionário Escolar da Língua Portuguesa Michaellis (2008, p. 577, grifo do autor), a Mística significa "1. Tratado a respeito das coisas divinas e espirituais. 2. Misticismimo", e analisando o misticismo no mesmo Dicionário: "1.Crença religiosa ou filosófica dos místicos, que admitem comunicações ocultas entre os homens e a 
divindade. 2. Aptidão ou tendência para crer no sobrenatural. 3. Devoção religiosa; vida contemplativa."

Outros sentidos para o termo "Mística" encontram-se no Dicionário da Educação do Campo no verbete escrito por Bogo (2012), o qual destaca que há pelo menos três possibilidades de explicações das manifestações das experiências místicas: pela religiosidade, pelas ciências políticas e pelos movimentos sociais.

Pensando no aspecto religioso, Bogo (2012, p. 473), referenciando Boff, diz que:

[...] as experiências religiosas, desde a antiguidade, tratam a mística como 'espiritualidade'. Nessas experiências, ela aparece como atitudes pelas quais o ser social se sente parte, ligado e re-ligado ao todo que é o cosmos. A persistência nas mesmas atitudes éticas, durante a toda vida na prática social de seres sociais ou de sujeitos coletivos, conforme a experiência do fazer como parte do movimento da continuidade da vida e da história.

A Mística na experiência religiosa, naturalmente reflete a dimensão do sagrado, do espiritual e daquilo que transcende as explicações terrenas.

Nesse sentido, a Mística foi um elemento fundamental utilizado na atuação da Comissão Pastoral da Terra $-\mathrm{CPT}^{3}$ por meio do trabalho de base realizado junto às comunidades e lideranças na luta pela terra.

\footnotetext{
${ }^{3}$ A Comissão Pastoral da Terra (CPT) nasceu em junho de 1975, durante o Encontro de Pastoral da Amazônia, convocado pela Conferência Nacional dos Bispos do Brasil (CNBB), e realizado em Goiânia (GO). Inicialmente a CPT desenvolveu junto aos trabalhadores e trabalhadoras da terra um serviço pastoral. Na definição de Ivo Poletto, que foi o primeiro secretário da entidade, "os verdadeiros pais e mães da CPT são os peões, os posseiros, os índios, os migrantes, as mulheres e homens que lutam pela sua liberdade e dignidade numa terra livre da dominação da propriedade capitalista".

Fundada em plena ditadura militar, como resposta à grave situação dos trabalhadores rurais, posseiros e peões, sobretudo na Amazônia, a CPT teve um importante papel. Ajudou a defender as pessoas da crueldade deste sistema de governo, que só fazia o jogo dos interesses capitalistas nacionais e transnacionais, e abriu caminhos para que ele fosse superado. Ela nasceu ligada à Igreja Católica porque a repressão estava atingindo muitos agentes pastorais e lideranças populares, e também, porque a igreja possuía uma certa influência política e cultural. Na verdade, a instituição eclesiástica não havia sido molestada.

No período da ditadura, o reconhecimento do vínculo com a Conferência Nacional dos Bispos do Brasil (CNBB) ajudou a CPT a realizar o seu trabalho e se manter. Mas já nos primeiros anos, a entidade adquiriu um caráter ecumênico, tanto no sentido dos trabalhadores que eram apoiados, quanto na incorporação de agentes de outras igrejas cristãs, destacadamente da Igreja Evangélica de Confissão Luterana no Brasil - IECLB. (Fonte: http://www.cptnacional.org.br/index.php/quem-somos/-historico ; acesso em 24/08/2015).
} 
A CPT utilizava a Mística na propagação dos valores religiosos com uma leitura revolucionária, como destaca Stedile e Fernandes (2012, p. 22):

[...] com o surgimento da CPT, é a pastoral. Penso que é um elemento importante de aplicação prática do que foi o Concílio Vaticano II e das outras encíclicas progressistas que surgiram. E que, de certa forma, acabou sendo expresso pela Teologia da Libertação 4 . A CPT foi a aplicação da Teologia da Libertação na prática, o que trouxe uma contribuição importante para as lutas camponesas pelo prisma ideológico. Os padres, agentes pastorais, religiosos e pastores discutiam com os camponeses a necessidade de eles se organizarem.

A Teologia da Libertação nasceu na Igreja Católica como resposta à contradição existente na América Latina entre a pobreza extrema e a fé cristã de sua população.

A partir da Teologia da Libertação, a Mística passa a ser considerada experiência globalizante, integrando a vivência espiritual à vivência social em sua prática.

$\mathrm{Na}$ segunda possibilidade de explicação das manifestações das experiências místicas, Bogo (2012) destaca a Mística pelas ciências políticas:

[...] as revelações subjetivas no entendimento das ciências políticas são compreendidas como expressões do 'carisma' que há em cada ser social. As qualidades particulares ou habilidades próprias de cada indivíduo são colocadas a serviço da coletividade e tornam-se contribuições identificadas com cada tipo de sujeito. As qualidades particulares, que diferem um indivíduo do outro no fazer concreto, revela que, na subjetividade, é impossível desvendar os 'mistérios' das habilidades carismáticas que fazem os indivíduos assumirem funções de liderança, ocuparem o seu tempo com questões superiores ao interesse comum da coletividade, correrem riscos por insistirem em destacar-se e colocar-se à frente dos processos de mudanças, quando milhares de sujeitos como ele não o fazem (BOGO, 2012, p. 473, grifo do autor).

Logo, as qualidades e dons de cada indivíduo se configuram como fundamentos de carisma, que, por meio das habilidades essenciais de cada um, movimenta-se num coletivo com objetivos específicos de uma causa ou de um projeto.

\footnotetext{
${ }^{4}$ Teologia da Libertação - Corrente pastoral das Igrejas Cristãs que aglutina agentes da pastoral, padres e bispos progressistas que desenvolveram uma prática voltada para a realidade social.
} 
De acordo com Bogo (2002), existem autores que, em vez da palavra "mística", preferem usar a palavra "carisma". A diferença entre elas está numa análise mais focada na "sociologia política e menos na visão antropológica e cultural" (BOGO, 2002, p. 19).

Assim, se as propostas dos Movimentos Sociais passam pela construção de um projeto social que supere o modelo liberal, então a motivação coletiva e individual passa pelo estímulo da prática Mística, no sentido antropológico mais amplo. Nesse aspecto, Bogo (2002, p. 177) afirma que "são muitas as tarefas da Mística".

Além disso, esse elemento destaca a criação de uma nova consciência com valorização no ser humano que supere a quantificação mercadológica de consumidores descartáveis e que impulsione a motivação na construção de valores. A Mística seria capaz de dar essa motivação para que o "desânimo e a falta de esperanças sejam dominados e vencidos" (BOGO, 2002, p.177).

Nessa perspectiva, Leonardo Boff (2010) destaca que a palavra mistério significa mysterion, que em grego provém de múein, que quer dizer "perceber o caráter escondido, não comunicado de uma realidade ou intenção".

Bogo (2012) destaca, como terceira possibilidade de manifestações místicas, a experiência dos movimentos sociais:

[...] pela fundamentação filosófica, os movimentos populares compreendem a mística como expressões da cultura, da arte e dos valores como parte constitutiva da experiência edificada na luta pela transformação da realidade social, indo em direção aos topos, a parte realizável da utopia. A linguagem das atitudes verbais e não verbais dos movimentos populares expressa o que são e o que querem estes sujeitos das mudanças sociais. Fundamentalmente, os movimentos camponeses, a partir do final do século $X X$, compreenderam que a totalidade do projeto de mudanças sociais não se realiza apenas pela força e pela inteligência, os sentimentos e a afetividade também fazem parte do projeto e não podem ser ignorados. A subjetividade de cada um torna-se objetividade no processo que efetiva a antecipação da utopia (BOGO, 2012, p. 474, grifo do autor).

Como um sentimento de utopia, a "mística se coloca como a paixão que anima a militância" e se concretiza como ação representativa da mudança que almeja e que tem a ver com a finalidade do sonho e com o caminho percorrido para alcançá-lo (PELOSO, 1994). 
Nas últimas décadas, "os movimentos populares tiveram a ousadia de assumir a mística, dando a ela um conteúdo próprio" (BOGO, 2012), utilizandoa como símbolo que impulsiona as experiências de lutas e também as utopias.

Nessa caminhada, a corrente da Teologia da Libertação teve um importante papel para a estruturação do MST, o que possibilitou, por meio do trabalho de base dos agentes religiosos, a ascensão da luta pela reforma agrária.

Entretanto, a prática litúrgica da Igreja engessava formalmente a celebração da vida e a história do Movimento. Por isso, e aos poucos, a Mística passou a não se encaixar mais dentro dos rituais moldados pelas Igrejas. Era necessário constituir uma nova forma de expressar a própria caminhada. Nesse sentido é que o MST inova dentro deste contexto, passando a vivenciar sua visão própria de Mística.

Assim, oficializado em 1984, o MST assume as ações contemplando e ressignificando a prática vivenciada até o momento junto aos agentes religiosos.

A Mística do MST recebe outro sentido para sua realização, como destaca Pizetta (2007, p. 96), sendo vivenciada como um:

[...] mecanismo de celebrar, de cultivar o projeto político, por intermédio dos símbolos, da cultura, da memória, dos sonhos. A mística ensina a cultivar o projeto; por isso, não existe projeto sem mística, como não existe mística sem projeto, sem causa. A massa deve ser contagiada pela mística para que possa carregar em seus braços a causa da revolução, da liberdade.

Nesse contexto, a Mística expressa a cultura, a arte, a política, a economia, a memória de um povo e os diversos valores de justiça e indignação, edificando a luta pela transformação. Peloso (1994, p. 5) destaca que o jeito de expressar a Mística é sempre diferente, porque as pessoas e a realidade são diferentes:

Não pode ser igual no sul e no norte, no campo e na cidade, no meio dos cristãos e dos não-cristãos, entre homens e mulheres, para os jovens e os adultos. A tentativa de 'exportar' os 'modelos' é sempre encarada como uma imposição arrogante, mesmo que não tenha sido de propósito. [...] A celebração da mística entre os negros não pode esquecer seus ritos, seus ritmos, seus valores culturais, seus protestos e sua religião. Assim como entre os gaúchos tem que incorporar seus costumes, sua dança, seus trajes típicos e suas sadias tradições. E assim, em todas 
as regiões junto com a cultura e a geografia, a mística leva em conta as histórias de luta do povo.

Considerando as ações do MST na realização da Mística, Bogo (2002, p. 53 - 136) destaca cinco aspectos que sustentam e conduzem a Mística numa perspectiva ética e revolucionária:

A causa e os sonhos: A causa é, por um lado, a razão pela qual vivemos e lutamos, mas é também a estruturação dos meios para realizá-la. Quem não tem causa, não tem sentido para se organizar, para se mover; aceita a dominação sem reclamar. [...]

A consciência: A consciência acima de tudo é o conhecimento. Não existe consciência sem conhecimento. [...] A consciência, porém, não é um bloco fechado constituído de um jeito apenas. Ela se movimenta, se desdobra e evolui de acordo com os conhecimentos e experiências adquiridas. [...]

A ética e a moral: A mística também é alimentada pela ética e amoral. Elas organizam a conduta dos lutadores. [...] $\mathrm{O}$ que unifica ética e moral? São os princípios. Os princípios ${ }^{5}$, embora possam ser interpretados diferentemente e evoluam em seu conteúdo com o decorrer dos tempos, são referências básicas, tanto para o comportamento social, quanto para a organização política ou para um movimento social.

A simbologia: Quando tratamos de utopia, devemos dizer que ela se compõe de fantasias que formulamos e corremos atrás para alcançá-las. [...] Os símbolos fazem parte da mística porque eles materializam os sentimentos, as vontades, os sonhos e criam sua própria linguagem, ultrapassando a realidade do visível. [...]

A arte: Com a forma da consciência estética é que se relaciona $a$ arte. Esta forma de consciência é constituída por sentimentos, gostos, impressões, imaginação etc., tanto assim que, a estética, palavra de origem grega 'aisthesis', é definida como a 'faculdade de sentir' ou a 'compreensão pelos sentidos'. [...] A arte acompanhou a produção da existência; foi e é parte da cultura. Ajuda a compor a consciência estética dos indivíduos e dos grupos sociais.

A Mística está em movimento e está presente na luta por projetos e políticas públicas essenciais aos povos do campo, resguardando sua identidade e cultura.

\footnotetext{
${ }^{5}$ Princípio é o que está na origem das coisas, ou o que fundamenta, sustenta e garante a preservação dos aspectos centrais da filosofia. Em tudo há princípios. Interessa aqui tratarmos dos princípios na política (BOGO, 2002, p. 77).
} 
Atualmente, a Mística faz-se presente na Educação do Campo como um elemento pedagógico importante na produção e ressignificação do conhecimento, sobretudo no reconhecimento da identidade coletiva, da memória e também, como fortalecimento da luta do movimento pela Educação do Campo.

Pizetta (2002) destaca que a Mística é uma prática que se manifesta com teoria, conteúdo e ideologia, a qual, utilizando as categorias da dialética, evidencia-se com conteúdo e forma. Esses dois aspectos se requerem e se impulsionam e, ao mesmo tempo, proporcionam o desenvolvimento político no cotidiano da militância e o enriquecimento do imaginário dos sonhos e esperanças para o cultivo de um projeto.

Na educação, pela experiência do Instituto de Educação Josué de Casto, pode-se perceber que:

A mística integra em nosso método pedagógico a intencionalidade do trabalho nessa dimensão da convivência. Aprendendo do MST, no IEJC se considera que a mística é uma forma de cultivar sobretudo sentimentos combinados com convicções e valores que nos ajudam a enfrentar os desafios de cada momento, de cada conjuntura. Ela trabalha no intercâmbio humano no patamar simbólico-artístico, ideológico e emocional e, na escola, precisa ser compreendida como mais do que um tempo educativo. A mística é 'uma energia que perpassa o cotidiano. Por isso precisamos dela no início das grandes atividades e resgatada em vários momentos do dia. Ela é a forma de já ir concretizando, no aqui e agora, a nossa utopia' (ITERRA, 2004) (CALDART et al., 2013, p. 345).

$\mathrm{Na}$ Educação do Campo, a Mística esteve presente nos diversos momentos, alimentando o sentimento de pertença das comunidades camponesas na discussão e construção do projeto de educação.

Nesse contexto, existe um movimento dentro das escolas do campo pesquisadas, onde a Mística é compreendida enquanto elemento pedagógico importantíssimo na produção e ressignificação do conhecimento. 
Fotografia 1 - Mística

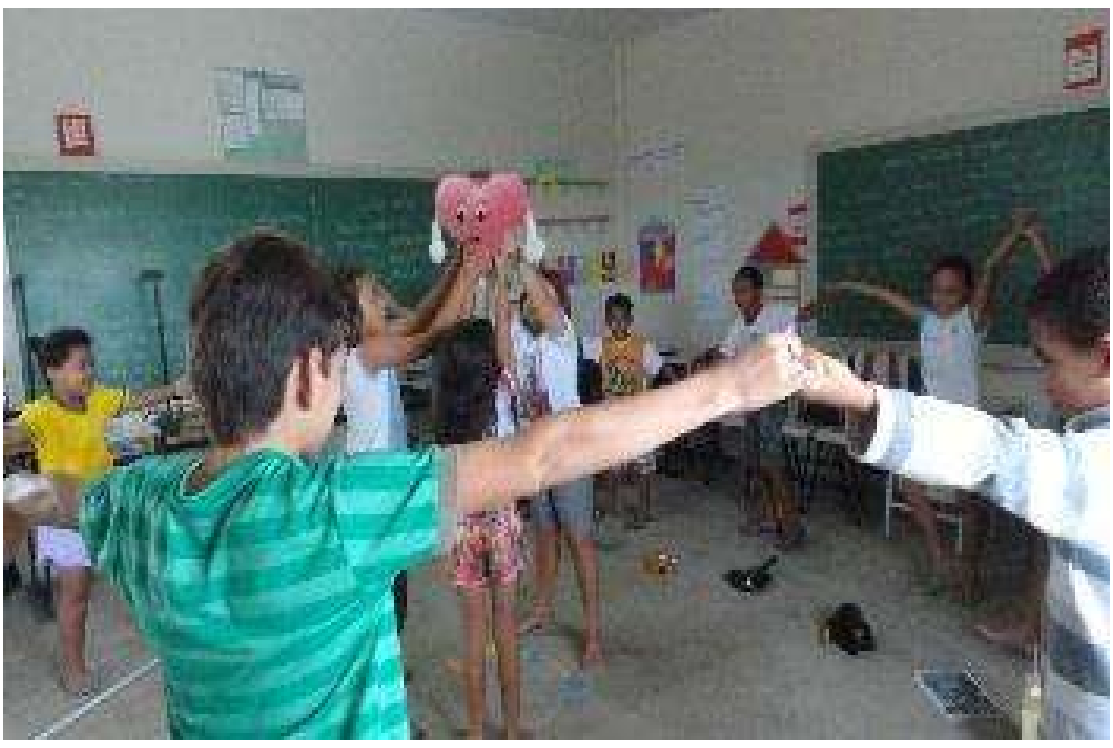

Fonte: EPM São Sebastião do Zanelato (2015).

Fotografia 2 - Mística

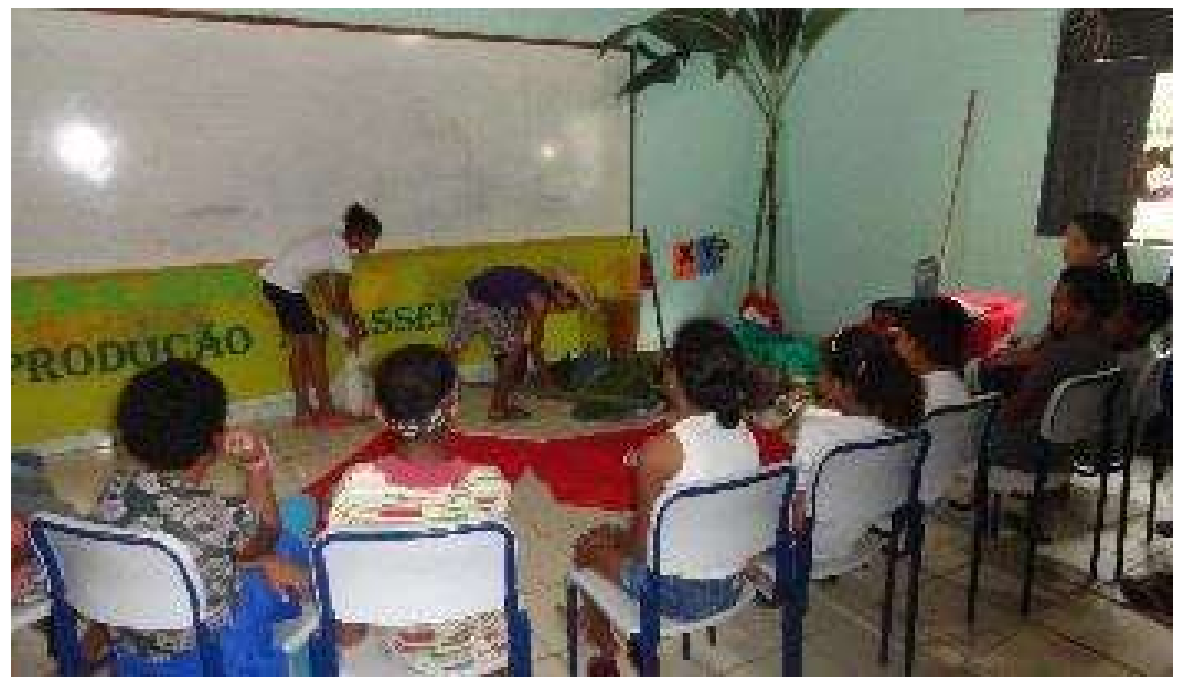

Fonte: EEEF XIII de Setembro (2015).

Durante a pesquisa nas escolas foi possível perceber a Mística do ambiente escolar por meio da organização do espaço com simbologias do campo, na acolhida da pesquisa pelos estudantes da EPM São Sebastião do Zanelato e foi muito emocionante vivenciar esse momento com os estudantes. A Mística esteve presente em mais duas escolas - a EEEF XIII de Setembro e a EPM Bernadete de Lourdes - que estavam desenvolvendo atividades relacionadas ao Plano de Estudo com os estudantes. 
As propostas pedagógicas de Jaguaré, São Mateus e do MST destacam a Mística nos diversos momentos pedagógicos da escola, utilizando-a como um elemento essencial nas principais ações desenvolvidas no cotidiano da escola.

A proposta utilizada no Município de Jaguaré destaca que a Mística deve se manifestar:

[...] na organização do espaço escolar, no preparo da alimentação, no alimentar-se, no cuidado com a horta, na motivação do Tema de Plano de Estudo, em suma, em diversos momentos educativos. Assim, um ambiente escolar místico, em uma escola do campo, é aquele organizado de forma dialógica, com ornamentos e objetos significativos para a cultura e os saberes camponeses; com cadeiras organizadas de forma circular, em que os sujeitos possam se olhar e se respeitar; com apresentações culturais que dialoguem com esta realidade. Enfim, o espaço escolar deve ser também, um instrumento de emancipação, de reflexão do pensamento crítico (MACROCENTRO NORTE E EXTREMO NORTE DO ESTADO DO ESPÍRITO SANTO, 2011-2013, p. 31, grifo nosso).

Sobre a Mística apresentada pela EPM São Sebastião do Zanelato durante a realização da pesquisa na escola, a educadora ${ }^{6}$ Ruth Vailati Fidêncio Arariba (2015) destaca que:

Na verdade a Mística ela não é feita por mim, nós organizamos juntos, trabalhando, essa música, um tema bacana, o que a gente pode envolver dessa música para fazer uma apresentação? Ah tia se a gente fizesse isso? Vamos pegar o cachorro! Eu tenho! Eu trago o meu! Eles que... Junto comigo... eu não faço sozinha (ARARIBA, 2015).

No PLAFEC - Plano de Fortalecimento da Educação do Campo, proposta pedagógica do Município de São Mateus, a Mística também recebe um importante destaque nas etapas do Plano de Estudo e no momento da autoorganização, o que possibilita a sua realização nos diversos momentos do cotidiano escolar.

\footnotetext{
${ }^{6}$ Ruth Vailati Fidêncio Arariba, educadora da EPM São Sebastião do Zanelato, localizada no Córrego do Mosquito, Município de Jaguaré-ES. Entrevista concedida a Ozana Luzia Galvão Baldotto, São Mateus, 20 mar. 2015.
} 
A educadora ${ }^{7}$ Jane do Carmo de Jesus de Souza, da EPM Enedino Monteiro, relata a utilização da Mística na introdução do Plano de Estudo com os estudantes

[...] nos anos anteriores eu fiz um vídeo com eles da primeira moradora da comunidade, eles tem um vídeo dela dando entrevista, para você ver, a Mística, a motivação, essa questão de motivar eles para o plano de estudos, o ano passado no quinto ano eles prepararam a Mística, eu já agrupei eles, o quinto ano eles fizeram um vídeo, a cultura camponesa, eles apresentaram em forma de vídeo, no terceiro e quarto ano eles apresentaram em forma de ilustrações a Mística, do ano passado. Este ano como foi a Mística? Trabalhei uma música, [...], para o tema a Minha Família, nós fizemos uma coreografia, aí a Mística para os alunos foi a motivação de uma música (SOUZA, J, do C.de J. de, 2015).

Importante destacar que esse trabalho iniciou-se em São Mateus no ano de 2012, envolvendo os educadores das escolas multisseriadas, como relata a educadora:

Aí sim, por fazer esse trabalho todo, conhecer um pouco da história, a metodologia, os instrumentos da Escola do $\mathrm{Km} \mathrm{41,}$ tive a oportunidade de visitar também escolas de Jaguaré na época com você, aí manuseamos, essa questão da Mística. Então assim, essa dificuldade de estar manuseando o PLAFEC eu não tive muito, estou aprendendo cada dia coisas novas, e aí em 2012, aí foi onde nós tivemos a formação, o meu primeiro portfólio com o PLAFEC (SOUZA, J, do C.de J. de, 2015).

Essencial destacar que a educadora se coloca na posição de estudante e aprendiz de sua prática, o que é fundamental para a efetivação da proposta pedagógica no contexto em que a escola está inserida, neste caso, em região de pescadores.

Djoni do Nascimento (2015) destaca que "a motivação ela garante, a meu ver, $50 \%$ da atividade do Plano de Estudo". A Mística faz parte dessa motivação e os estudantes são protagonistas desse momento:

Ai a gente vai tentando colocar o aluno para ele ser mais protagonista ainda do que o professor, no caso, a gente orienta, mas o aluno que vai fazer mais, produzir mais. No ano passado essa Mística, quem fazia era nós. Nós que fazíamos a Mística,

\footnotetext{
${ }^{7}$ Jane do Carmo de Jesus de Souza, educadora da EPM Enedino Monteiro, localizada na Barra Nova Sul, Município de São Mateus-ES. Entrevista concedida a Ozana Luzia Galvão Baldotto, São Mateus, 5 maio. 2015.
} 
hoje se eu pedir um estudante, "ah, faz uma Mística montada para mim, por favor, vocês vão fazer uma Mística relacionada ao tema tal", eu fico observando e eles fazem a Mística, e tem tudo a ver com o contexto do tema. Então o aluno hoje, ele já é mais protagonista na questão do plano de estudo, na questão da motivação, [...], mas isso a gente vem trabalhando também no dia a dia (NASCIMENTO, D. do, 2015).

Nessa mesma unidade escolar, durante o diálogo com os estudantes sobre o trabalho realizado em sala de aula com o Plano de Estudo, a estudante 8 Tayná Tiburcio Carvalho (2015), destaca que:

Nós organizamos a Mística, alguns estudantes entram apresentando as culturas, aí a gente canta a música com relação ao tema, depois faz a motivação, dividimos o grupo, saímos pra fora pra montar as perguntas, aí depois nós lemos a pergunta lá para os professores (CARVALHO, 2015).

As escolas utilizam a Mística como um elemento pedagógico no cotidiano escolar e no processo formativo dos estudantes. No entanto, cabe destacar que não se trata de utilizá-la como uma tarefa ou dinâmica, minimizando o sentido desse elemento.

Nesse contexto, Caldart (2013) chama atenção para a padronização desse elemento pedagógico:

[...] a mística, do ponto de vista de sua natureza, em certo sentido estética, deve estar submetida a pressupostos pedagógicos, ideológicos, ou seja, a serviço de um objetivo. Nesse sentido, sua eficácia fica comprometida, tornando-se algo didático, palatável, formal. Quer dizer com palatável que, à medida que a mística se enquadra em padrões, em formalidade, perde o seu sentido originário de motivação, de animação, seja para a luta, seja para outras tarefas, como a do estudo (CALDART, 2013, p. 348).

Em contrapartida, faz-se importante destacar que, à medida que as apresentações vão se desenvolvendo no cotidiano escolar:

[...] vão se criando padrões, intencionais ou não, pois o ato de fazer a mística também é um ato de cópia, mas não uma cópia fiel, pois se assim fosse, as místicas seriam todas iguais.

\footnotetext{
${ }^{8}$ Tayná Tiburcio Carvalho, estudante da EPM Bernadete de Lourdes Bastos, localizada na Rod. 381, Miguel Curry Carneiro, Km 29, Município de São Mateus-ES. Entrevista concedida a Ozana Luzia Galvão Baldotto, São Mateus, 14 abr. 2015.
} 
Dizemos "cópia" porque sempre se mantém algo de uma apresentação para outra (CALDART, 2013, p. 348).

A Mística possui aspectos essenciais que a posicionam como revolucionária (BOGO, 2002), como um momento que precisa contagiar, cultivar, celebrar e até denunciar as injustiças. Assim, a utilização da Mística enquanto elemento pedagógico requer uma fundamentação, preparação e atenção especial pelo coletivo escolar, resguardando sempre o seu sentido.

O sentimento produzido pela Mística mobiliza as pessoas em direção a um ideal e prepara as pessoas para buscar esse ideal. Na Educação do Campo, esse ideal se direciona à "ocupação" das escolas do campo com o projeto específico discutido com o povo que vive no campo.

Nessa perspectiva, a respeito da legitimidade da estratégia de ocupação, José Gomes da Silva, ex-presidente do Instituto Nacional de Colonização e Reforma Agrária (Incra), enfatiza que:

As ocupações existem porque, no contexto social que vivenciamos, o ocupante procura por trabalhos em espaços vazios, abandonados, sem destinação, empurrado pela necessidade de fome, de trabalho, como imperativo de emergência. Assim, em razão de ser famélica esta ocupação, ela não pode ser punível. Ocupar terra para plantio [e para moradia] não é delito; delito é o estoque especulativo de terras. Merecem punição, de acordo com a lei, os proprietários que mantêm a terra ociosa, sem destinação social (SILVA, J. G. da, 1996, p. 2).

No contexto educacional, a ocupação das escolas representa a luta por direito a educação, contextualizada e condizente com os povos do campo, com valorização da cultura e identidade desses povos.

Nessa direção, existe, ainda, a luta por escola e sua manutenção, considerando as demandas administrativas e o contexto pedagógico ao qual a unidade escolar encontra-se inserida. Em muitas ocasiões, a ocupação de órgãos públicos acontece para que estes assumam sua responsabilidade em oferecer o ensino e, em outros momentos, pela contratação de profissionais e, assim, sucessivamente. Os povos do campo lutam incansavelmente para movimentar as escolas do campo e "fazer valer o direito a uma educação digna". 
Nessa perspectiva, Lindomar Panni ${ }^{9}$ (2015) relembra o percurso para efetivar a especificidade da Educação do Campo no Município de São Mateus:

[...] a ideia de fazer uma discussão com as famílias aqui da região [região do assentamento Zumbi dos Palmares - São Mateus] e criar então um grupo mais amplo de discussão em relação à educação no Município de São Mateus, que a gente via que as escolas, que tinha no Município, no campo elas estavam se perdendo, iam fechar. Em muitas regiões, as famílias optavam leigamente por deixar com que levasse para onde quisesse os filhos para estudar, então não se tinha resistência. Como nós resolvemos puxar a discussão naquele momento, então outras comunidades se inseriram, e teve um resultado significativo, que foi a partir dessa discussão, desse fato [...] que foi criada uma comissão de educação no Município e daí pôde expandir a discussão para a região do Córrego Seco, onde foi criada a escola lá, a ECORM que já iniciou com a pedagogia da alternância e aí com o tempo podendo garantir os instrumentos, num segundo momento começou aqui no Zumbi [...]. E eu acho que o fruto dessa discussão que gerou a necessidade de criar um núcleo de Educação do Campo dentro da própria secretaria de educação [São Mateus] (PANNI, L., 2015).

Onde está a Mística nessa situação?

Como não rememorar as palavras de Pizetta (2007, p. 96) mediante a lembrança de Panni durante a realização desse diálogo "A Mística ensina a cultivar o projeto; por isso, não existe projeto sem Mística, como não existe Mística sem projeto, sem causa".

Nesse contexto reside a essência da Mística que alimentou a memória de uma causa coletiva e, como destaca Bogo (2002), a memória fica marcada pelos fenômenos que temos capacidade de produzir seja na "vida pessoal, no companheirismo, nas atitudes, no trabalho produtivo, na participação, na maneira de fazer as reuniões, nas mobilizações, no zelo ao cumprir cada tarefa (PELOSO, p. 09 1994).

Nessa perspectiva, Edgar Soares dos Santos $^{10}$ destaca a utilização da Mística na realização da pesquisa com os estudantes:

\footnotetext{
9 PANNI, Lindomar, Professor da EMEIEF Assentamento Zumbi dos Palmares, localizada no Assentamento Zumbi dos Palmares, Município de São Mateus-ES. Entrevista concedida a Ozana Luzia Galvão Baldotto, São Mateus, 6 maio. 2015.

${ }^{10}$ Edgar Soares dos Santos, Educador da EEEF XIII de Setembro, localizada no Assentamento Córrego da Areia, Município de Jaguaré-ES. Entrevista concedida a Ozana Luzia Galvão Baldotto, São Mateus, 24 junh. 2015.
} 
Na primeira semana já precisa aplicar a introdução [do Plano de Estudo], que é preciso fazer uma motivação para os educandos buscarem conhecimento com as famílias, e aí é feito toda a Mística, toda a preparação, a gente prepara da melhor forma possível, com carinho, para que eles realmente sintam vontade mesmo de buscar, aprofundar naquela temática. $E$ aí a gente vai atrás muito assim, cada vez a gente busca meios para que realmente traga sempre uma novidade para eles, e aí nesse sentido a gente faz esse debate com eles, leva música, leva pequenos vídeos, é leva poemas, depoimentos dos próprios pais, comunidade e tal, vem pra fazer depoimento e tal, então pra gente estar fortalecendo o entendimento apriorístico sobre a importância de pesquisar, da importância da pesquisa, porque a pesquisa é à priori, assim, fundamental para que eles consigam aprofundar nas discussões do curso (SANTOS, E. S. dos, 2015).

O educador exemplifica a prática pedagógica com os estudantes, no entanto a Mística está presente como um elemento que sustenta essa ação no cotidiano escolar.

Durante o diálogo com os estudantes da EMEIEF Assentamento Zumbi dos Palmares sobre o Plano de Estudo, eles trouxeram a Mística como um momento marcante e que gostam muito no cotidiano da escola. Perguntado às crianças qual parte do Plano de Estudo que mais gostam, Gustavo Menon Silva $(2015)^{11}$ foi taxativo: "Da Mística", quem completou o raciocínio foi Ariane A. dos Santos (2015):

Eu [gosto] da Mística e também que eu não sabia antes como que era o tempo, que eu não tinha nascido ainda, aí fala muitas coisas sobre a ocupação, sobre os povos antigos, num tem? Assim, vai falando e a gente cada vez vai aprendendo mais (SANTOS, A. A. dos, 2015).

A estudante destaca os conteúdos que aprendeu durante as Místicas que participou na escola. Nesse contexto, a Mística é considerada um elemento essencial na proposta pedagógica das escolas do campo, por toda a sua abrangência, movimento e por possibilitar o protagonismo dos estudantes na sua construção e execução.

11Gustavo Menon Silva: estudante do $5^{\circ}$ ano do Ensino Fundamental na EMEIEF Assentamento Zumbi dos Palmares, morador do assentamento Zumbi dos Palmares, São Mateus-ES. Entrevista concedida a Ozana Luzia Galvão Baldotto, São Mateus, 6 maio. 2015. 
Importante relatar aqui a memória do início da Educação do Campo na rede municipal de São Mateus, em 2010, em que a Mística sempre esteve presente em todos os momentos de reuniões, atos realizados pelas famílias camponesas e nas atividades pedagógicas realizadas pelas escolas do campo. As Místicas daquele momento sempre trouxerem muito conteúdo e a mensagem presente naquele período era a definição do que era uma escola do campo e o direito à educação aos povos do campo.

A Mística tornou-se um elemento pedagógico de fundamental importância no cultivo e construção da modalidade Educação do Campo, sendo utilizada como estratégia de consolidação da identidade dos sujeitos do campo, possuindo, assim, no processo de aprendizagem, um papel extremamente formativo.

Portanto, muito presente na religiosidade, a Mística foi tomando contornos de um movimento de luta e denúncia, contemplando a utopia, sem perder a memória que fortalece a identidade e a cultura de um povo.

\section{Considerações Finais}

A Mística migrou dos espaços do sagrado para o contexto das lutas sociais, assumindo múltiplos sentidos. Ela esteve presente desde o surgimento do Movimento dos trabalhadores Rurais Sem Terra - MST, em suas primeiras ocupações, acampamentos, assentamentos e segue em tempos atuais nos mais variados espaços do movimento como: congressos, reuniões, encontros, cursos, seminário e nos diversos atos realizados como bandeiras de luta.

Ao longo da trajetória do Movimento da Educação do Campo no país, a Mística esteve presente marcando o tempo e o espaço com foco na construção desse projeto voltado a identidade dos povos do campo.

Sim! A Mística alimenta a caminhada e motiva a luta por uma causa ou projeto, pela dimensão de elementos e conteúdos que mobiliza para trabalhar determinado tema.

Dessa forma, ela é considerada um elemento essencial nos projetos pedagógicos das escolas do campo nos Municípios de Jaguaré e São Mateus 
por possibilitar o envolvimento dos diversos povos do campo na construção e fortalecimento desses projetos.

Nesse sentido, a Mística é um elemento com diversas dimensões capaz de educar, politizar, manter viva a memória de um povo, mobilizar e contribuir para a consolidação da identidade cultural do sujeito, um elemento enriquecedor da Educação do Campo.

\section{Referências}

ARARIBA, Ruth Vailati Fidêncio. Educação do Campo em movimento: dos planos à ação pedagógica em escolas multisseriadas e anos iniciais de São Mateus e Jaguaré (ES). Educadora da EPM São Sebastião do Zanelato, localizada no Córrego do Mosquito, Município de Jaguaré-ES. Entrevista concedida a Ozana Luzia Galvão Baldotto, São Mateus - ES, 20 mar. 2015.

BALDOTTO, Ozana Luzia Galvão. Mística na EEEF XIII de Setembro, São Mateus, ES, 2015. 2015. 1 fotografia.

BALDOTTO, Ozana Luzia Galvão. Mística na EPM São Sebastião do Zanelato, Jaguaré, ES, 2015. 2015. 1 fotografia.

BETTO, Frei. Mística e compromisso social. In: BETTO, Frei; BOFF, Leonardo. Mística e espiritualidade. Petrópolis, RJ: Vozes, 2010. p. 103-106.

BOFF, Leonardo. Que é mística? In: BETTO, Frei; BOFF, Leonardo. Mística e espiritualidade. Petrópolis, RJ: Vozes, 2010. p. 49-68.

BOGO, Ademar. Mística. In: CALDART, Roseli Salete et al (Orgs.). DICIONÁRIO DA EDUCAÇÃO DO CAMPO. São Paulo: Expressão Popular, 2012. p. 473 477.

BOGO, Ademar. O Vigor da Mística. Caderno de cultura, $\mathrm{n}^{\circ}$ 02. [S.I.]: MST, 2002.

CALDART, Roseli Salete et al. Escola em Movimento: Instituto de Educação Josué de Castro. 1. ed. São Paulo: Expressão Popular, 2013.

CARVALHO, Tayná Tiburcio. Educação do Campo em movimento: dos planos à ação pedagógica em escolas multisseriadas e anos iniciais de São Mateus e Jaguaré (ES). Estudante da EPM Bernadete de Lourdes Bastos, localizada na Rod. 381, Miguel Curry Carneiro, Km 29, Município de São Mateus-ES. Entrevista concedida a Ozana Luzia Galvão Baldotto, São Mateus, 14 abr. 2015.

COMISSÃO PASTORAL DA TERRA. Massacres no Campo. 2010. Disponível em: http://www.cptnacional.org.br/index.php/quem-somos/-historico . Acesso em: 24 ago.2015. 
MACROCENTROS NORTE E EXTREMO NORTE DO ESTADO DO ESPÍRITO SANTO. Orientações Curriculares para os Anos Iniciais do Ensino Fundamental das Escolas do Campo do Espírito Santo. Produção 20112013. 127 p.

MEIHY, José Carlos Sebe B; HOLANDA, Fabíola. História Oral: como fazer, como pensar. 2 ed.. São Paulo: Contexto, 2010.

MICHAELIS. Dicionário Escolar da Língua Portuguesa. São Paulo: Editora Melhoramentos, 2008. Edição revisada pelo Acordo Ortográfico da Língua Portuguesa.

MOVIMENTO DOS TRABALHADORES RURAIS SEM TERRA - MST. Como fazemos a escola de Educação Fundamental. Caderno de Educação $n^{\circ} 09$. Nov./1999. 48 f.

NASCIMENTO, Djoni do. Educação do Campo em movimento: dos planos à ação pedagógica em escolas multisseriadas e anos iniciais de São Mateus e Jaguaré (ES). Professor da EPM Bernadete de Lourdes Bastos, localizada na Rod. 381, Miguel Curry Carneiro, Km 29, Município de São Mateus-ES. Entrevista concedida a Ozana Luzia Galvão Baldotto, São Mateus - ES, 14 abr. 2015.

PANNI, Lindomar. Educação do Campo em movimento: dos planos à ação pedagógica em escolas multisseriadas e anos iniciais de São Mateus e Jaguaré (ES). Professor da EMEIEF Assentamento Zumbi dos Palmares, localizada no Assentamento Zumbi dos Palmares, Município de São Mateus-ES. Entrevista concedida a Ozana Luzia Galvão Baldotto, São Mateus - ES, 6 mai. 2015.

PELOSO, Ranulfo. A Força que anima os militantes. São Paulo: MST, 1994. p. 10.

PEREIRA, Wesley Pereira. Poema: O verdadeiro sentido da mística. In: SÃO MATEUS - ES. Educação do Campo: caminho novo com a Pedagogia da Alternância. 2011. p. 33. Estudante do $9^{\circ}$ ano, EMEIEF Assentamento Zumbi dos Palmares.

PIZETTA, Adelar João. A formação de quadros políticos: elaboração teórica, experiências e atualidade. In: Escola Nacional Florestan Fernandes. A política de formação de quadros. Cadernos de estudos n. 1. 2007. p. 91-99.

PIZETTA, Adelar João. Apresentação. In: BOGO, Ademar. O Vigor da Mística. Caderno de cultura, $n^{\circ}$ 02. [S.I.]: MST, 2002. p. 07-12.

SAMPAIO, Plínio de Arruda. A mística. Estudos, depoimentos e referências. Novem. 2002. Disponível em:http://www.landlessvoices.org/vieira/archive05. php?rd=MSTICAOF657\&ng $=$ p\&sc $=3 \&$ th $=42 \&$ se $=0$.

SANTOS, Ariane Alexandre dos. Educação do Campo em movimento: dos planos à ação pedagógica em escolas multisseriadas e anos iniciais de São Mateus e Jaguaré (ES). Estudante da EMEIEF Assentamento Zumbi dos 
Palmares, localizada no Assentamento Zumbi dos Palmares, Município de São Mateus-ES. Entrevista concedida a Ozana Luzia Galvão Baldotto, São Mateus ES, 6 maio. 2015.

SANTOS, Edgar Soares dos. Educação do Campo em movimento: dos planos à ação pedagógica em escolas multisseriadas e anos iniciais de São Mateus e Jaguaré (ES). Educador da EEEF XIII de Setembro, localizada no Assentamento Córrego da Areia, Município de Jaguaré-ES. Entrevista concedida a Ozana Luzia Galvão Baldotto, São Mateus, 24 junh. 2015.

SECRETARIA MUNICIPAL DE EDUCAÇÃO DE SÃO MATEUS - ES. PLAFEC Plano de Fortalecimento da Educação do Campo. São Mateus, ES: [s.n.], 2012. 43 p.

SECRETARIA MUNICIPAL DE EDUCAÇÃO E CULTURA DE JAGUARÉ. PROVER Programa de Valorização da Educação Rural. Jaguaré, ES: [s.n.], 2006. $18 \mathrm{p}$.

SILVA, Gustavo Menon. Educação do Campo em movimento: dos planos à ação pedagógica em escolas multisseriadas e anos iniciais de São Mateus e Jaguaré (ES). Estudante da EMEIEF Assentamento Zumbi dos Palmares, localizada no Assentamento Zumbi dos Palmares, Município de São Mateus-ES. Entrevista concedida a Ozana Luzia Galvão Baldotto, São Mateus - ES, 6 mai. 2015.

SILVA, José Gomes da. A reforma agrária brasileira na virada do milênio. São Paulo: Abra, 1996.

SOUZA, Jane do Carmo de Jesus de. Educação do Campo em movimento: dos planos à ação pedagógica em escolas multisseriadas e anos iniciais de São Mateus e Jaguaré (ES). Professora da EPM Enedino Monteiro, localizada na Barra Nova Sul, Município de São Mateus-ES. Entrevista concedida a Ozana Luzia Galvão Baldotto, São Mateus, 5 maio. 2015.

STEDILE, João Pedro; FERNANDES, Bernardo Mançano. Brava gente: a trajetória do MST e a luta pela terra no Brasil. 2 Ed. São Paulo: Expressão Popular, 2012.

ZAMBERLAN, Sérgio. Pedagogia da Alternância: Escola da Família Agrícola. Coleção Francisco Giust 1. Anchieta: MEPES - Movimento de Educação Promocional do Espírito Santo. 1995.

\section{Sobre os autores}

\section{Ozana Luzia Galvão Baldotto}

ozananv@yahoo.com.br

Mestre pelo Programa de Pós-Graduação em Ensino na Educação Básica (PPGEEB) Universidade Federal do Espírito Santo - UFES, São Mateus-ES, Brasil; Pedagoga na Rede Municipal de Ensino de São Mateus, na função de 
Gestora da Educação do Campo - Secretaria Municipal de Educação de São Mateus - Espírito Santo, Brasil.

\section{Ailton Pereira Morila}

apmorila@gmail.com

Doutor e mestre em educação pela Faculdade de Educação da USP. Bacharel em História pela Faculdade de Filosofia, Letras e Ciências Humanas da USP. Engenheiro Mecânico pela Escola de Engenharia de São Carlos-USP. Professor Associado da Universidade Federal do Espírito Santo. Membro Permanente do Programa de pós-graduação em Ensino na Educação Básica da UFES. 